\title{
Clinical effects of transcatheter hepatic arterial embolization with holmium-166 poly(L-lactic acid) microspheres in healthy pigs
}

\author{
M. A. D. Vente • J. F. W. Nijsen • T. C. de Wit • \\ J. H. Seppenwoolde - G. C. Krijger • P. R. Seevinck • \\ A. Huisman • B. A. Zonnenberg • \\ T. S. G. A. M. van den Ingh - A. D. van het Schip
}

Received: 25 July 2007 / Accepted: 4 February 2008 /Published online: 11 March 2008

(C) The Author(s) 2008

\begin{abstract}
Purpose The aim of this study is to evaluate the toxicity of holmium-166 poly(L-lactic acid) microspheres administered into the hepatic artery in pigs.

Methods Healthy pigs $(20-30 \mathrm{~kg})$ were injected into the hepatic artery with holmium-165-loaded microspheres $\left({ }^{165} \mathrm{HoMS} ; n=5\right)$ or with holmium-166-loaded microspheres $\left({ }^{166} \mathrm{HoMS} ; n=13\right)$. The microspheres' biodistribution was assessed by single-photon emission computed
\end{abstract}

M. A. D. Vente $(\varangle) \cdot$ J. F. W. Nijsen · T. C. de Wit •

A. D. van het Schip

Department of Nuclear Medicine,

University Medical Center Utrecht,

P.O. Box 85500, 3508 GA Utrecht, The Netherlands

e-mail: m.vente@umcutrecht.nl

J. H. Seppenwoolde • P. R. Seevinck

Image Sciences Institute, University Medical Center Utrecht,

Utrecht, The Netherlands

\section{G. C. Krijger}

Department of Radiation, Radionuclides and Reactors,

Faculty of Applied Sciences, Delft University of Technology,

Delft, The Netherlands

\section{A. Huisman}

Department of Clinical Chemistry and Haematology,

University Medical Center Utrecht,

Utrecht, The Netherlands

\section{B. A. Zonnenberg}

Department of Internal Medicine,

University Medical Center Utrecht,

Utrecht, The Netherlands

T. S. G. A. M. van den Ingh

TCCI Consultancy B.V.,

P.O. Box 85032, 3508 AA Utrecht, The Netherlands tomography and/or MRI. The animals were monitored clinically, biochemically, and $\left({ }^{166} \mathrm{HoMS}\right.$ group only) hematologically over a period of 1 month $\left({ }^{165} \mathrm{HoMS}\right.$ group) or over 1 or 2 months ( ${ }^{166}$ HoMS group). Finally, a pathological examination was undertaken.

Results After microsphere administration, some animals exhibited a slightly diminished level of consciousness and a dip in appetite, both of which were transient. Four lethal adverse events occurred in the ${ }^{166} \mathrm{HoMS}$ group due either to incorrect administration or comorbidity: inadvertent delivery of microspheres into the gastric wall $(n=2)$, preexisting gastric ulceration $(n=1)$, and endocarditis $(n=1)$. AST levels were transitorily elevated post ${ }^{166} \mathrm{HoMS}$ administration. In the other blood parameters, no abnormalities were observed. Nuclear scans were acquired from all animals from the ${ }^{166}$ HoMS group, and MRI scans were performed if available. In pigs from the ${ }^{166} \mathrm{HoMS}$ group, atrophy of one or more liver lobes was frequently observed. The actual radioactivity distribution was assessed through ex vivo ${ }^{166 \mathrm{~m}} \mathrm{Ho}$ measurements. Conclusion It can be concluded that the toxicity profile of HoMS is low. In pigs, hepatic arterial embolization with ${ }^{166} \mathrm{HoMS}$ in amounts corresponding with liver-absorbed doses of over $100 \mathrm{~Gy}$, if correctly administered, is not associated with clinically relevant side effects. This result offers a good perspective for upcoming patient trials.

Keywords Internal radiation therapy · Holmium ·

Microspheres $\cdot$ Liver malignancies

\section{Introduction}

Internal radiation therapy with yttrium-90 $\left({ }^{90} \mathrm{Y}\right)$-loaded microspheres injected into the hepatic artery has demonstrated to 
be an effective treatment option in the management of patients with unresectable intrahepatic malignancies [1-5]. Two ${ }^{90} \mathrm{Y}$ microsphere products are currently commercially available and in clinical use: TheraSphere ${ }^{\circledR}$ (MDS Nordion Inc., Kanata, Ontario, Canada) and SIR-Spheres ${ }^{\circledR}$ (SIRTeX Medical Ltd., Sydney, New South Wales, Australia). These two devices differ considerably in physical characteristics, particularly with regard to density and specific activity (Table 1); TheraSphere ${ }^{\circledR}$ microspheres are glass microspheres, consequently not biodegradable, and more importantly, of a high density compared to plasma [6]. This may increase the risk of proximal intravascular settling [7]. SIRSpheres ${ }^{\circledR}$ are resin-based microspheres of near-plasma density [8]. A disadvantage of SIR-Spheres ${ }^{\circledR}$ is the relatively low specific activity [9], which necessitates the administration of relatively high amounts of these microspheres. This has been reported to frequently lead to retrograde flow and/or failure to deliver the intended dose $[10,11]$.

For tumor dosimetry calculations, quantitative imaging is essential, which would also allow assessment of the radiation dose delivered to the non-tumorous liver tissue. As ${ }^{90} \mathrm{Y}$ is a pure beta emitter, the only way to (quantitatively) assess the biodistribution of the SIR-Spheres ${ }^{\circledR}$ and TheraSphere ${ }^{\circledR}$ microspheres would be by means of Bremsstrahlung scans of which the quality has unfortunately been demonstrated to be insufficient for this purpose. At the nuclear medicine department of the University Medical Center Utrecht (Utrecht, The Netherlands), holmium-166 poly(L-lactic acid) microspheres $\left({ }^{166} \mathrm{HoMS}\right)$ have been developed, which have several advantageous properties when compared with the available ${ }^{90} \mathrm{Y}$ microspheres. The most important advantage of the use of holmium is in imaging and therefore also in dosimetry. Since ${ }^{166} \mathrm{Ho}$ is a combined beta-gamma emitter (Table 1), these microspheres allow for quantitative nuclear imaging [12]; this allows that, instead of using technetium-99m-labeled albumin macroaggregates to predict the biodistribution of the microspheres [13] particularly in identification of excessive shunting to the lungs, stomach, and/or duodenum-a small tracer dose of ${ }^{166} \mathrm{HoMS}$ can be applied. Secondly, after administration of the therapeutic dose, its distribution can be accurately assessed. In addition, as holmium is a highly paramagnetic element, it is suitable for (quantitative) MRI [14, 15], especially useful for medium- and long-term monitoring of the intrahepatic behavior of the holmium microspheres. This property also allows for real-time visualization of the deposition of microspheres during a (fully) MRI-guided selective administration [16]. Other advantageous features of holmium are its higher dose rate and its higher neutronabsorption cross-section (Table 1), as a consequence of which, considerably shorter reactor time is needed.

The pharmaceutical quality of the ${ }^{166} \mathrm{HoMS}$ has been extensively investigated and proven to be satisfactory [1719]. Furthermore, it must have been demonstrated, with aid of adequate animal studies, that the device is expected to be efficacious. Therefore, a non-survival biodistribution study in rats was performed in which it was demonstrated that the microsphere deposition was restricted to the tumor-bearing liver lobe and that, in the tumorous tissue, the radioactivity concentration was six times higher than in the non-target liver tissue [20]. To definitely demonstrate that ${ }^{166} \mathrm{HoMS}$ injected into the hepatic artery have a tumoricidal effect, an efficacy study in Vx2 carcinoma bearing rabbits was performed [21]. In all animals treated with ${ }^{166} \mathrm{HoMS}$, tumour growth was arrested and necrosis set in. Finally, before initiation of a phase 1 clinical trial, it must be ascertained that the toxicity profile of the device will be acceptable. An extensive toxicity study in (non-tumorbearing) pigs has therefore been conducted. The porcine model was chosen mainly for its body size, as a catheterization procedure is involved in the treatment for which the smaller laboratory animal species are unsuitable [22]. The aim of this study was to investigate the acute and medium-term toxicity of the ${ }^{166} \mathrm{HoMS}$ and to ascertain potential complications associated with the catheterizationadministration procedure.
Table 1 Microsphere characteristics

${ }^{\mathrm{a}}$ Calculated values

\begin{tabular}{llll}
\hline Microsphere & TheraSphere ${ }^{\circledR}$ & SIR-Spheres $^{\circledR}$ & $\begin{array}{l}\text { Holmium } \\
\text { microspheres }\end{array}$ \\
\hline Radionuclide & Yttrium-90 & Holmium-166 \\
Radionuclide properties & & & 26.8 \\
$T_{1 / 2}(\mathrm{~h})$ & 64.1 & & $1.77(48.7 \%), 1.85(50.0 \%)$ \\
Maximum $\beta^{-}$-energy (MeV) & $2.28(99.9 \%)$ & & $80.6(6.7 \%)$ \\
$\gamma$-Energy $(\mathrm{keV})$ & No $\gamma$-emission & & 64 \\
Neutron cross-section (barn) & 1.3 & Resin & Poly(L-lactic acid) \\
Matrix material & Glass & 1.6 & 1.4 \\
Density $(\mathrm{g} / \mathrm{ml})$ & 3.3 & $32 \pm 10$ & $30 \pm 5$ \\
Diameter $(\mu \mathrm{m})$ & $25 \pm 10$ & $50^{\mathrm{a}}$ & $450^{\mathrm{a}}$ \\
Activity/microsphere $(\mathrm{Bq})$ & $1,250^{\mathrm{a}}-2,500$ & $50,000,000$ & $33,000,000$ \\
Number of microspheres per dose & $4,000,000$ & & \\
& & &
\end{tabular}




\section{Materials and methods}

\section{Study design}

The study was divided into two substudies: The aim of the first substudy, which consisted of five pig experiments, was to evaluate the clinical effects of transcatheter hepatic arterial administration of escalating amounts of (non-radioactive) ${ }^{165}$ HoMS (7.5-37.5 mg/kg in steps of $7.5 \mathrm{mg} / \mathrm{kg}$ ); the second substudy consisted of 13 pigs that were administered ${ }^{166}$ HoMS (200-300 mg) with the aim of assessing the clinical effects of increasing amounts of radioactivity, starting at $3.15 \mathrm{MBq}{ }^{166} \mathrm{Ho} / \mathrm{g}$ liver tissue. Escalation of administered activity was implemented in increments of $3.15 \mathrm{MBq} / \mathrm{g}$ up to $9.45 \mathrm{MBq}{ }^{166} \mathrm{Ho} / \mathrm{g}$ liver tissue, corresponding with an absorbed liver dose of 50, 100, and $150 \mathrm{~Gy}$, respectively. Each group was intended to consist of two to four animals, depending on the encountered side effects. Animals in the ${ }^{165}$ HoMS group were sacrificed 1 month after microsphere administration and the animals in the ${ }^{166}$ HoMS group randomized to termination 1 or 2 months post-administration.

\section{Animals}

Eighteen healthy female pigs, 3-4 months old, weighing 20-30 kg, and specified pathogen-free, were obtained from the Animal Sciences Group, Wageningen University and Research Center, Lelystad, The Netherlands. A 2-week acclimatization period was allowed. The animals were kept under conventional conditions with ad libitum access to tap water and given standard pelleted feed twice a day. The experiments were conducted in agreement with the local applicable Dutch law, "Wet op de dierproeven" (art. 9, 1977) and the European Convention for the Protection of Vertebrate Animals used for Experimental and Other Scientific Purposes (1986), and approved by the ethical committee for animal experimentation of the University Medical Center Utrecht, Utrecht, The Netherlands (DECGNK no. 03.03.032).

\section{Microsphere preparation}

Good manufacturing practice (GMP) grade ${ }^{165}$ HoMS were prepared as previously described [18, 23]. In the case of the radioactive substudy, the microspheres were packed in high-density polyethylene vials (Posthumus Plastics, Beverwijk, The Netherlands) and neutron-activated via the ${ }^{165} \mathrm{Ho}[\mathrm{n}, \gamma]{ }^{166} \mathrm{Ho}$ reaction in the nuclear reactor of the Delft University of Technology (Delft, The Netherlands) with a thermal neutron flux of $5 \times 10^{12} \mathrm{~cm}^{-2} \mathrm{~s}^{-1}$ for a predetermined length of time (1.5-7.5 h). After arrival at the hospital, the microspheres were suspended in $1 \mathrm{ml}$ of a
Pluronic $^{\circledR}$ solution [24] and transferred into a glass Vbottom vial. The amount of radioactivity was then measured in a dose calibrator (VDC-404, Veenstra Instrumenten B.V., Joure, The Netherlands).

Anesthesia and analgesia

Premedication for general anesthesia consisted of azaperon (4 mg/kg), ketamine hydrochloride (10 mg/kg), and atropine $(0.1 \mathrm{mg} / 10 \mathrm{~kg}) \mathrm{IM}$. Induction of general anesthesia consisted of thiopental (5-10 mg/kg) or propofol $(2.5-3.5 \mathrm{mg} / \mathrm{kg}) \mathrm{IV}$. General anesthesia was maintained by continuous intravenous infusion of $8-9 \mathrm{mg} / \mathrm{kg}$ per hour propofol or by inhalation of isoflurane $(1.5-2.0 \%)$ in $\mathrm{O}_{2}$ /air $(1: 1)$ in combination with midazolam hydrochloride $(0.2 \mathrm{mg} / \mathrm{kg})$ IV. Perioperative analgesia was provided by sufentanil (loading dose, $5 \mu \mathrm{g} / \mathrm{kg}$; maintenance dose, $10 \mu \mathrm{g} / \mathrm{kg}$ per hour) IV. Perioperative antibiotic prophylaxis consisted of a preoperative dose of amoxicillin with clavulanic acid (10 mg/ $\mathrm{kg}) \mathrm{IV}$.

Postoperative medication consisted of buprenorphine $(0.015 \mathrm{mg} / \mathrm{kg})$ and carprofen $(4 \mathrm{mg} / \mathrm{kg}) \mathrm{IV}$, and ampicillin (7.5 $\mathrm{mg} / \mathrm{kg}$ ) IM. The animals were terminated by an overdose of sodium pentobarbitone (100-200 mg/kg) IV after ketamine sedation.

\section{Chronic intravascular catheter}

For convenient withdrawal of blood samples and administration of medication, a 7F silicone catheter (Instech Solomon, Plymouth Meeting, PA, USA) was inserted into the external jugular vein and immobilized and then subcutaneously tunneled to exit dorsally between the scapulas. The postoperative protocol consisted of daily flushing with saline and injection of a heparin saline solution into the catheter and topical antibacterial prophylaxis (procaine benzylpenicillin $200,000 \mathrm{IE} / \mathrm{ml}$ + dihydrostreptomycin $200 \mathrm{mg} / \mathrm{ml}$ ) on the exit site for 2 weeks.

\section{Catheterization and microsphere administration}

An Avanti ${ }^{\circledR}+$ catheter sheath introducer (5F, Cordis Europe N.V., Roden, The Netherlands) was inserted into the right femoral artery. The catheters deployed in the experiments were Performa ${ }^{\circledR}$ Modified Hook Flush, Softouch ${ }^{\circledR}$ Osborn 2 and Softouch ${ }^{\circledR}$ Straight Flush, in combination with double-ended (J-tip and straight tip) and straight fixed core (super stiff) guide wires (Merit Medical Europe, MaastrichtAirport, The Netherlands). The tip of the catheter was positioned in A. hepatica propria, i.e., in the hepatic artery, distally to where the gastroduodenal artery branches off. The microspheres were flushed out of the vial and into the catheter by injecting $15-20 \mathrm{ml}$ of saline solution into the vial at a rate of $0.5-1.0 \mathrm{ml} \mathrm{s}^{-1}$. 
Imaging protocols

Microsphere distribution was assessed by single photon emission computed tomography (SPECT), planar nuclear imaging, and (if available) MRI, 3 days post-administration. Immobilization was obtained by propofol, after premedication with ketamine. The SPECT and MRI scans were acquired according to previously described protocols $[12,14]$.

\section{Dosimetry}

The absorbed liver doses were calculated as follows. For ${ }^{166} \mathrm{Ho}$, the calculated absorbed energy is $15.87 \mathrm{~mJ} \mathrm{MBq}^{-1}$, based on $S$ values, as calculated by Dr. M. W. Konijnenberg (Mallinckrodt Inc., Tyco Healthcare, Petten, The Netherlands) through the use of the Monte-Carlo MCNPX code (Los Alamos National Laboratory, Los Alamos, New Mexico, USA). Assuming that all energy is absorbed in the liver, the cumulative dose ( $\mathrm{mGy} \mathrm{MBq}^{-1}$ ) may be calculated to be $15.87 \mathrm{~mJ} \mathrm{MBq}^{-1} /$ liver weight $(\mathrm{kg})$. The weight of the porcine liver equates to $1.97 \%$ of the body weight [25]. Thus, for example, in a pig of $25 \mathrm{~kg}$ with a liver of approximately $490 \mathrm{~g}$ in which $4,500 \mathrm{MBq}{ }^{166} \mathrm{Ho}$ is administered, the absorbed organ dose is $15.87 \times 10^{-3} \mathrm{~J} \mathrm{MBq}^{-1} \times 4,500 \mathrm{MBq} /$ $0.490 \mathrm{~kg}=146 \mathrm{~Gy}$.

\section{Clinical follow-up}

The animals were monitored for clinical side effects on a daily basis. Clinical parameters monitored included demeanor, consciousness level/alertness, posture and gait, food intake, and growth (the animals were weighed twice a week).

Blood samples were taken before microsphere administration (baseline values), $10 \mathrm{~min}$ after delivery of the microspheres, and twice a week until termination. Hemoglobin $(\mathrm{Hb})$, leukocyte count, and platelet count were determined within $4 \mathrm{~h}$ of sampling using a Cell-Dyn ${ }^{\circledR} 4000$ hematology analyzer (Abbott Laboratories, Santa Clara, CA, USA). Prothrombin time (PT) was determined within $4 \mathrm{~h}$ of sampling using a STA ${ }^{\circledR}$ coagulation analyzer (Diagnostica Stago, Asnières, France). Plasma samples for chemical analyses were stored after centrifugation and kept frozen at $-20^{\circ} \mathrm{C}$ until analysis. Gamma-glutamyltransferase (GGT), alkaline phosphatase (ALP), alanine aminotransferase (ALT), aspartate aminotransferase (AST), and bilirubin were analyzed, using a Vitros $^{\circledR} 950$ chemistry system (Ortho Clinical Diagnostics, Rochester, NY, USA).

Postmortem examination

After termination, a gross pathological examination was performed, during which the liver and gallbladder, spleen, lungs, and stomach were collected and processed for histological examination. Tissue sections (4- $\mu \mathrm{m}$ thick) were routinely prepared and stained with hematoxylin and eosin and evaluated by light microscopy.

Ex vivo radioactivity distribution assessment

The liver and gallbladder, spleen, lungs, and stomach of the animals, which had been administered with ${ }^{166} \mathrm{HoMS}$, were processed into a homogeneous suspension using a kitchen blender and chemical destruction (sodium hydroxide $8.25 \mathrm{mmol} / \mathrm{l})$. For every organ suspension, the content of holmium-166 metastable ( ${ }^{166 \mathrm{~m}} \mathrm{Ho}, T_{1 / 2} \approx 1,200$ years) was measured directly using a low-background gamma-counter (Tobor, Nuclear Chicago, Chicago, IL, USA). During neutron activation, both ${ }^{166} \mathrm{Ho}$ and ${ }^{166 \mathrm{~m}} \mathrm{Ho}$ are formed $\left({ }^{166} \mathrm{Ho} /{ }^{166 \mathrm{~m}} \mathrm{Ho} \approx 1,000,000: 1\right)$. Since the ${ }^{166 \mathrm{~m}} \mathrm{Ho}$ interorgan distribution is linear to the ${ }^{166} \mathrm{Ho}$ distribution, the interorgan radioactivity distribution of the ${ }^{166} \mathrm{HoMS}$ could then be calculated accurately.

\section{Results}

\section{Clinical follow-up}

In the non-radioactive experiments, the amount of ${ }^{165} \mathrm{HoMS}$ was escalated up to $700 \mathrm{mg}$, which on a bodyweight basis, corresponds to three times the amount that will be administered to patients. Whether the entire dosage was selectively deposited in the liver and whether or not a significant part of the injected microspheres had ended up in organs other than the liver could not be quantitatively assessed. In the radioactive experiments, between 1.4 and $6.5 \mathrm{GBq}{ }^{166} \mathrm{Ho}$ was administered, which (when corrected for extrahepatic deposition) equates to attained whole-liver nominal absorbed doses of between 59 and $162 \mathrm{~Gy}$; Table 2 gives an overview of the amounts of microspheres actually administered and, where appropriate, the real amounts of radioactivity that were delivered and, accordingly, the estimated absorbed liver doses.

After the catheterization-administration procedure, inappetence and a slightly diminished state of consciousness, both of which were transient, were observed in some animals in both substudies. Typically, in a couple of days, consciousness level and appetite returned to pretreatment levels. However, daily contact (for at least $20 \mathrm{~min}$ ) between researcher and pig beginning 2 weeks before the start of the experiment clearly advanced the return of appetite within 2 days for most of the animals.

In total, five serious adverse events were observed (Table 3). Complications that occurred were either due to erroneous microsphere delivery, i.e., extrahepatic deposition, or due to comorbidity, with the exception of pig 3 . 
Table 2 Overview of the pig experiments

\begin{tabular}{|c|c|c|c|c|c|c|c|c|c|}
\hline \multirow[t]{2}{*}{ Pig no. } & \multirow[t]{2}{*}{$\begin{array}{l}\text { Body weight } \\
(\mathrm{kg})^{\mathrm{a}}\end{array}$} & \multicolumn{4}{|c|}{ Administered dosage of HoMS } & \multirow[t]{2}{*}{$\begin{array}{l}\text { Absorbed liver } \\
\text { dose }(\mathrm{Gy})^{\mathrm{e}}\end{array}$} & \multicolumn{2}{|c|}{$\begin{array}{l}\text { Imaging } \\
\text { modalities }\end{array}$} & \multirow[t]{2}{*}{$\begin{array}{l}\text { Termination time } \\
\text { (days post-administration) }\end{array}$} \\
\hline & & $\mathrm{mg}^{\mathrm{b}}$ & $\mathrm{MBq}$ & $\begin{array}{l}\text { Specific activity } \\
(\mathrm{MBq} / \mathrm{mg})^{\mathrm{c}}\end{array}$ & $\mathrm{MBq} / \mathrm{g}$ liver $^{\mathrm{d}}$ & & MRI & SPECT & \\
\hline 1 & 21.8 & 159 & - & - & - & - & - & - & 30 \\
\hline 2 & 18.0 & 320 & - & - & - & - & - & - & 30 \\
\hline 3 & 18.7 & 430 & - & - & - & - & - & - & 30 \\
\hline 4 & 18.0 & 599 & - & - & - & - & - & - & 30 \\
\hline 5 & 19.4 & 700 & - & - & - & - & + & - & 30 \\
\hline 6 & 21.9 & 294 & 1,786 & 6.1 & 4.1 & $66(50)$ & + & + & 30 \\
\hline 7 & 19.0 & 240 & 2,439 & 10.2 & 6.5 & $103(100)$ & + & + & 60 \\
\hline 8 & 18.2 & 281 & 4,409 & 15.7 & 6.3 & $101(150)$ & - & + & 6 \\
\hline 9 & 19.3 & 221 & 1,410 & 6.4 & 3.7 & $59(50)$ & + & + & 60 \\
\hline 10 & 20.0 & 244 & 3,133 & 12.8 & 3.8 & $60(100)$ & + & + & 5 \\
\hline 11 & 20.1 & 297 & 2,657 & 8.9 & 6.7 & 107 (100) & + & + & 60 \\
\hline 12 & 19.1 & 278 & 2,846 & 10.2 & 7.6 & $120(150)$ & - & + & 20 \\
\hline 13 & 24.5 & 157 & 2,954 & 18.8 & 6.1 & $97(150)$ & + & + & 60 \\
\hline 14 & 26.4 & 138 & 3,371 & 24.4 & 6.5 & $103(150)$ & + & + & 30 \\
\hline 15 & 29.7 & 170 & 5,825 & 34.3 & 8.3 & $132(150)$ & + & + & 53 \\
\hline 16 & 28.8 & 191 & 5,874 & 30.8 & 6.7 & $106(150)$ & + & + & 30 \\
\hline 17 & 28.2 & 192 & 6,485 & 33.8 & 10.2 & $162(150)$ & - & + & 30 \\
\hline 18 & 29.3 & 223 & 5,895 & 26.4 & 7.4 & $118(150)$ & - & + & 60 \\
\hline
\end{tabular}

${ }^{a}$ Body weight at time of administration.

${ }^{b}$ Regarding the administered amount of microspheres in the non-radioactive experiments (pig no. 1-5) it was assumed that the entire administered dose was selectively deposited in the liver.

${ }^{\mathrm{c}}$ In the last six experiments specific activity was higher (hence number of microspheres lower) to reduce the risk of backflow.

${ }^{\mathrm{d}}$ According to literature (Boxenbaum et al., 1979) the weight of the porcine liver equates to $1.97 \%$ of its body weight. The portion of the administered amount of radioactivity actually delivered into the liver was calculated by measuring the ${ }^{166 \mathrm{~m}}$ Ho contents in the ex vivo organs.

${ }^{\mathrm{e}}$ The organ dose was calculated as follows: $\left[15.87 \mathrm{~mJ} \cdot \mathrm{MBq}^{-1} \cdot A(\mathrm{MBq}) / L W(\mathrm{~kg})\right] \times 10^{-3}$ (where $A$ is administered amount of radioactivity and $L W$ is liver weight). Intended liver dose is given between parentheses.

This animal was administered ${ }^{165}$ HoMS and experienced a paraparesis, probably attributable to a catheterizationrelated cord infarction that spontaneously resolved within $24 \mathrm{~h}$. In pigs 8 and 10 , treated with radioactive microspheres, clinically significant backflow into the gastroduodenal artery occurred. This artery conveys blood to the stomach, duodenum, and the pancreas and arises from the common hepatic artery, close to the origin of the right and left hepatic artery (Fig. 1a,b) [26]. Pig 8 expired from multifocal perforating gastric ulceration and peritonitis 6 days post-administration, and pig 10 was euthanized when excessive deposition of radioactivity in the stomach was observed on the nuclear scans. Pig 12 was diagnosed with severe persistent anemia $(\mathrm{Hb}<2.5 \mathrm{mmol} / \mathrm{l}) 1$ week post-operation and died from heart failure on day 20 . During postmortem examination, the animal was found to have suffered from multiple perforating gastric ulcers, which were not confined to the esophageal region. A

Table 3 Adverse events

\begin{tabular}{|c|c|c|c|}
\hline Pig no. & Adverse event & Comment & Clinical outcome \\
\hline 3 & Transient paraparesis & Ascribed to a spinal cord infarction & Resolved within $24 \mathrm{~h}$ \\
\hline 8 & $\begin{array}{l}\text { Acute peritonitis, necrosis of the stomach wall } \\
\text { and full-thickness gastric wall rupture }\end{array}$ & $\begin{array}{l}\text { Due to inadvertent administration of }{ }^{166} \mathrm{HoMS} \text { into } \\
\text { A. gastroduodenalis }\end{array}$ & Found dead at day 6 \\
\hline 10 & $\begin{array}{l}\text { Multifocal ulceration of the stomach, } \\
\text { one large perforating ulcer }\end{array}$ & $\begin{array}{l}\text { As a consequence of backflow of }{ }^{166} \mathrm{HoMS} \text { into } \\
\text { A. gastroduodenalis }\end{array}$ & Euthanized at day 5 \\
\hline 12 & $\begin{array}{l}\text { Chronic anemia due to persistently bleeding } \\
\text { ulcer }\end{array}$ & $\begin{array}{l}\text { Pepsinogen serum levels revealed that the peptic ulcer } \\
\text { was present before }{ }^{166} \mathrm{HoMS} \text { had been administered }\end{array}$ & $\begin{array}{l}\text { Demise from heart failure } \\
\text { at day } 20\end{array}$ \\
\hline 15 & $\begin{array}{l}\text { Endocarditis of the tricuspid valve, chronic } \\
\text { anemia due to persistently bleeding ulcer }\end{array}$ & $\begin{array}{l}\text { The endocarditis was most probably associated with } \\
\text { unhygienic blood withdrawal from the chronic } \\
\text { intravascular catheter }\end{array}$ & Euthanized at day 53 \\
\hline
\end{tabular}


Fig. 1 MR arteriography of the thorax and abdomen of a pig, anteroposterior projection (a); excerpt of a (b): common hepatic artery (1), splenic artery (2), caudal phrenic artery (3), gastroduodenal artery (4), (branches of the) proper hepatic artery (5), right hepatic artery (6), medial hepatic arteries (7), left hepatic artery $(8)$, and right gastric artery $(9)$
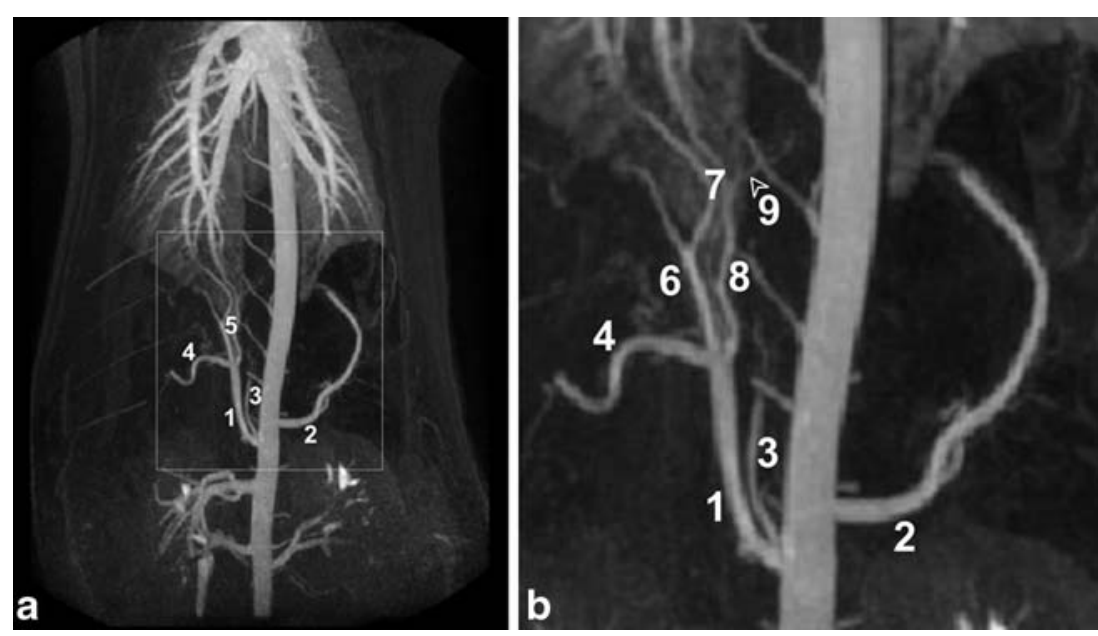

bleeding ulcer was most probably already present when the animal underwent ${ }^{166} \mathrm{HoMS}$ administration, as was demonstrated by the (difference in pre- and post-treatment) pepsinogen serum levels (data not shown). Pig 15 had to be euthanized prematurely because of its poor clinical condition; 7 weeks after ${ }^{166} \mathrm{HoMS}$ administration, it was found in a lethargic state, feverish, and unwilling to eat. It was also very anemic $(\mathrm{Hb}<3.0 \mathrm{mmol} / \mathrm{l})$ and exhibited signs of consumption coagulopathy. Despite antibacterial and antipyretic treatment, and supportive care, its condition continued to deteriorate and required euthanization at day 53. At necropsy, an endocarditis, most probably infective, was found, almost certainly associated with unhygienic blood withdrawal from the chronic intravascular catheter. Deep gastric ulcers were also found, the largest one being in the pars oesophagea of the stomach.

\section{Laboratory evaluation}

Hematological and (especially) hematochemical reference values of healthy pigs vary considerably between sources [27-29]. This is because different analysis methods had been used and because the measured values of some parameters are highly age-dependent (e.g., ALP, of which the serum levels are higher in growing animals). Most blood reference values from literature could therefore not be used in this study. Instead, it was decided to compare the mean values of the samples obtained post-treatment with the mean of the baseline values for each parameter.

The serum activities of GGT, ALP, and ALT exhibited no clinically relevant changes (Fig. $2 \mathrm{a}-\mathrm{c}$ ). In the ALP serum levels, a trivial difference was observed between the ${ }^{165} \mathrm{HoMS}$ group and the ${ }^{166} \mathrm{HoMS}$ group, which was already present in the baseline values. After radioactive microsphere administration, a moderate and transient elevation of AST levels was observed (Fig. 2d). In most samples, bilirubin was not detectable, and in the few in which it was detectable, levels did not surpass $4.0 \mu \mathrm{mol} / \mathrm{l}$ (data not shown). Mean hemoglobin levels were all higher than the mean of the hemoglobin baseline levels (Fig. 3a), even though the two animals diagnosed with severe persistent anemia were also included in the analysis. Similarly, platelet counts in the initial post-procedural samples were low, compared to those in samples collected later (Fig. 3b). The platelet counts varied considerably, both intra- and interindividually, but remained in the normal range. The mean total leukocyte count also remained within normal limits (Fig. 3c) [27]. Prothrombin time was not prolonged in any of the samples (Fig. 3d).

\section{Postmortem examinations}

The main pathological findings of the animals are summarized in Table 4. In the pigs that had been administered nonradioactive holmium microspheres, no gross abnormalities were seen, except for the liver of pig $3\left(22.5 \mathrm{mg}{ }^{165} \mathrm{HoMS} / \mathrm{kg}\right)$ in which the right lobes showed moderate atrophy and the left lobes slight (compensatory) hypertrophy. In one animal in this group, ulceration of the esophageal region of the stomach was seen. Moderate to marked atrophy of one or more liver lobes with compensatory hyperplasia of the other lobes was frequently observed in the animals treated with radioactive holmium microspheres (Table 4). In five animals (all from the ${ }^{166}$ HoMS substudy), moderate to extensive, often perforating, ulceration of the cardiac, fundic, and/or antral regions of the stomach was observed. In five animals, ulceration of the esophageal region of the stomach was seen (Table 4). In two animals, infarction of the gallbladder was observed (Table 4).

Histological examinations of the pigs of the ${ }^{165} \mathrm{HoMS}$ group regularly showed small and sometimes larger aggregates of microspheres in arteries of the liver, as well as some solitary intra-arteriolar microspheres in the stomach and gallbladder. Larger aggregates in the livers were associated 

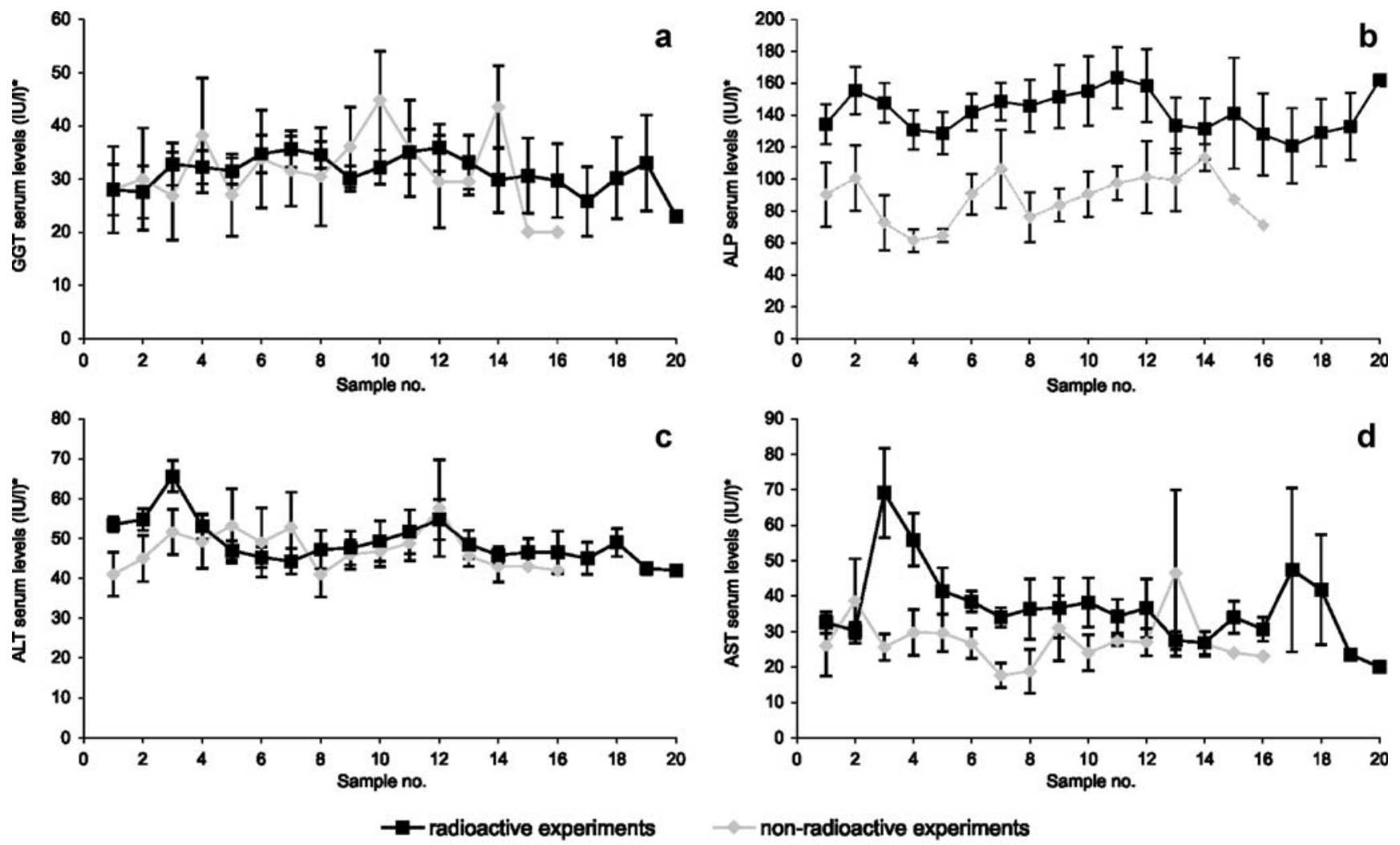

"Data are presented as mean values \pm SEM

Fig. 2 Liver enzymes serum activities. Time in between samples was 3 or 4 days, and value 1 was derived from samples taken before microsphere administration: serum activities of GGT (a), serum activities of ALP (b), serum activities of ALT (c), serum activities of AST (d)

with fibrosis and sometimes multinucleated giant cells surrounding individual spheres (Fig. 4a). In pig 3, in the right lateral liver lobe, a large portal area was seen with coagulative necrosis, surrounded by multinucleated giant cells, many pigmented macrophages and a fibrous capsule. In this capsule, some large aggregates of spheres were present (Fig. 4b). In the surrounding atrophic parenchyma, moderately broadened interlobular septa with fibrosis and arteriolar and ductular proliferation were seen; within these septa, small aggregates of microspheres were present. Histological examinations of pigs 8 and 10 in the ${ }^{166} \mathrm{HoMS}$ group, which died spontaneously at day 6 and was euthanized in extremis at day 5, respectively, showed multifocal aggregates in the hepatic arteries in the portal tracts. These aggregates were associated with complete necrosis of the portal area and the adjacent parenchyma (Fig. 4c). In the stomach of these animals, intra-arteriolar aggregates were sometimes seen, associated with thrombosis and necrosis of the arteriolar wall (Fig. 4d). In the other pigs in this group, which survived for 30 or 60 days, in the atrophic liver lobes, large aggregates of microspheres were frequently seen, associated with large areas of coagulative necrosis (often with yellow discoloration by bile imbibition) and surrounded by multinucleated giant cells, pigmented macrophages, and a fibrous capsule (Fig. 4e). In the two animals with infarction of the gallbladder, there was necrosis of the wall of the gallbladder with fibrous encapsulation. In the lumen of the gallbladder necrotic debris, inspissated bile and bile containing macrophages were present. An intraarteriolar aggregate was sometimes observed within the fibrous capsule (Fig. 4f). Histological examinations of the spleen in both groups showed only very rarely a solitary microsphere without additional histological changes. In none of the animals were microspheres seen in the lungs.

Imaging and microsphere biodistribution

Nuclear scans (planar and SPECT) were acquired in all 13 radioactive experiments. The distribution of radioactivity was assessed by ex vivo ${ }^{166 \mathrm{~m}}$ Ho measurements. Figure 5a shows a planar nuclear scan in which highly selective hepatic accumulation of the radioactivity is demonstrated, as was the case in seven animals in which, according to the ${ }^{166 \mathrm{~m}} \mathrm{Ho}$ measurements, more than $95 \%$ of the injected dose was deposited in the liver. On the scans of six animals, accumulation of ${ }^{166} \mathrm{HoMS}$ in the stomach was observed; although clinically inconsequential, on the scans of four pigs, a low to moderate amount of radioactivity $(<20 \%)$ was shown to be present in the stomach (Fig. 5b). In two other animals (pigs 8 and 10), the scans revealed excessive 

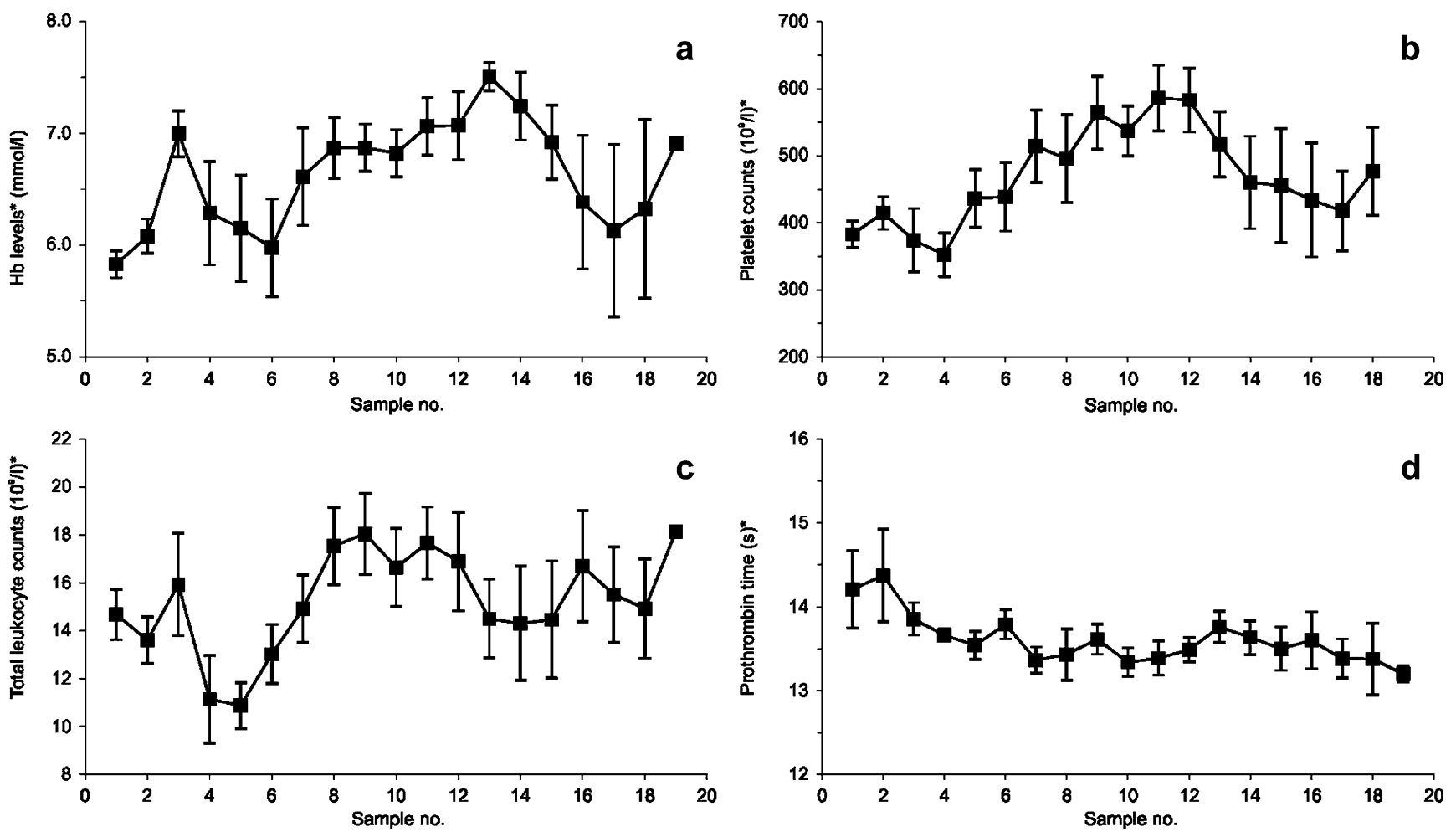

\section{radioactive experiments}

*Data are presented as mean values \pm SEM

Fig. 3 Hematological values. Time in between samples was 3 or 4 days, and value 1 was derived from samples taken before microsphere administration: hemoglobin concentrations (a), platelet counts (b), leukocyte counts (c), prothrombin time (d)

deposition of radioactivity in the gastric wall $(48 \%$ and $53 \%$ of injected activity, respectively; Fig. 5c). In none of the experiments was ${ }^{166} \mathrm{Ho}$ detected to be present in the lungs. This was in accordance with the histological examinations. In two animals, a portion of the radioactivity was delivered to the spleen $(\sim 10 \%)$. The nuclear scans revealed that the intrahepatic microsphere distribution was distinctly heterogeneous.

MRI scans were obtained in one non-radioactive experiment (pig 5) and in nine radioactive experiments (Table 2; Fig. 6a-f). While the intrahepatic distribution of the microspheres could be accurately assessed, demonstration of either presence or absence of microspheres in the lungs proved to be unfeasible, as the holmium-based artifacts on $T_{2}{ }^{*}$-weighted images are black, as is the air in the lungs. The presence of stomach gas and other contents also made it very difficult to assess whether microspheres had been deposited into the gastric wall.

\section{Discussion}

The clinical effects of (non-radioactive) ${ }^{165} \mathrm{Ho}$ and (radioactive) ${ }^{166} \mathrm{Ho}$ poly(L-lactic acid) microspheres when injected into the proper hepatic artery using a catheter were investigated in non-tumor-bearing pigs. With regard to the ${ }^{165}$ HoMS, it was investigated whether the administration of increasing amounts of microspheres would lead to signs of toxicity. The aim of the ${ }^{166}$ HoMS substudy was to evaluate the effects of escalating absorbed liver doses (from 50 up to 150 Gy). All animals were extensively monitored, both clinically, hematologically, and biochemically. After termination, a postmortem examination was undertaken. As quantitative ${ }^{166}$ Ho SPECT for clinical application is still in development, (the extent of) extrahepatic microsphere deposition was quantified through measuring the relative ${ }^{166 \mathrm{~m}}$ Ho content in organ homogenates.

Gastric ulcers have been a frequently encountered pathological finding in this study, located both in the esophageal region and in other parts of the stomach. Although gastric ulceration in the esophageal region is a very common abnormality in pigs and considered a mainly husbandry-related phenomenon [30], it nonetheless can have a fatal outcome (due to persistent hemorrhage). One animal in this study (pig 12) died as a consequence of very severe persistent gastric bleeding, and although the gastric ulcers found at gross pathological examination were not confined to the esophageal region, a bleeding ulcer was most probably already present when the animal underwent ${ }^{166}$ HoMS administration, as was demonstrated by the 
Table 4 Main pathological findings

\begin{tabular}{|c|c|c|c|c|c|}
\hline \multirow[t]{2}{*}{ Pig no. } & \multirow[t]{2}{*}{ Liver atrophy } & \multirow[t]{2}{*}{ Liver necrosis } & \multirow{2}{*}{$\begin{array}{l}\text { Gallbladder } \\
\text { infarction }\end{array}$} & \multicolumn{2}{|l|}{ Gastric ulcers } \\
\hline & & & & $\begin{array}{l}\text { Antrum, corpus } \\
\text { and/or fundus }\end{array}$ & $\begin{array}{l}\text { Esophageal } \\
\text { region }\end{array}$ \\
\hline 1 & - & - & - & - & + \\
\hline 2 & - & - & - & - & - \\
\hline 3 & $+(\mathrm{RL}, \mathrm{RM})$ & $+(\mathrm{RL})$ & - & - & - \\
\hline 4 & - & - & - & - & - \\
\hline 5 & - & - & - & - & - \\
\hline 6 & - & - & - & - & - \\
\hline 7 & - & - & - & - & - \\
\hline 8 & - & $+(\mathrm{RL})$ & - & + & - \\
\hline 9 & $+(\mathrm{RL})$ & - & - & - & - \\
\hline 10 & - & $+(\mathrm{RM})$ & - & + & - \\
\hline 11 & $+(\mathrm{RM}, \mathrm{LM})$ & $+(\mathrm{RM})$ & - & - & - \\
\hline 12 & $+(\mathrm{LL}, \mathrm{LM})$ & $+(\mathrm{RL}, \mathrm{RM}, \mathrm{LM}, \mathrm{LL})$ & - & + & + \\
\hline 13 & $+(\mathrm{LL}, \mathrm{LM})$ & - & - & - & - \\
\hline 14 & - & $+(\mathrm{HR}, \mathrm{RL}, \mathrm{LM})$ & + & - & - \\
\hline 15 & $+(\mathrm{LM}, \mathrm{LL})$ & $+(\mathrm{RL}, \mathrm{LM}, \mathrm{LL})$ & - & + & + \\
\hline 16 & $+(\mathrm{RL}, \mathrm{RM})$ & $+(\mathrm{RM})$ & + & - & + \\
\hline 17 & $+(\mathrm{LM}, \mathrm{LL})$ & $+(\mathrm{LM}, \mathrm{LL})$ & - & + & - \\
\hline 18 & $+(\mathrm{RM}, \mathrm{LM}, \mathrm{LL})$ & $+(\mathrm{RL}, \mathrm{RM})$ & - & - & + \\
\hline
\end{tabular}

$H R$ hilar region, $L M$ left medial lobe, $L L$ left lateral lobe, $R L$ right lateral lobe, $R M$ right medial lobe starting in the acclimatization period, both to help them get acquainted with the researcher and to provide a diversion from daily routine. Pig 15 also developed a severe anemia due to bleeding ulcers, but because the onset was more than 6 weeks post-treatment, it was certainly not related to the microsphere treatment. As this animal also suffered from a
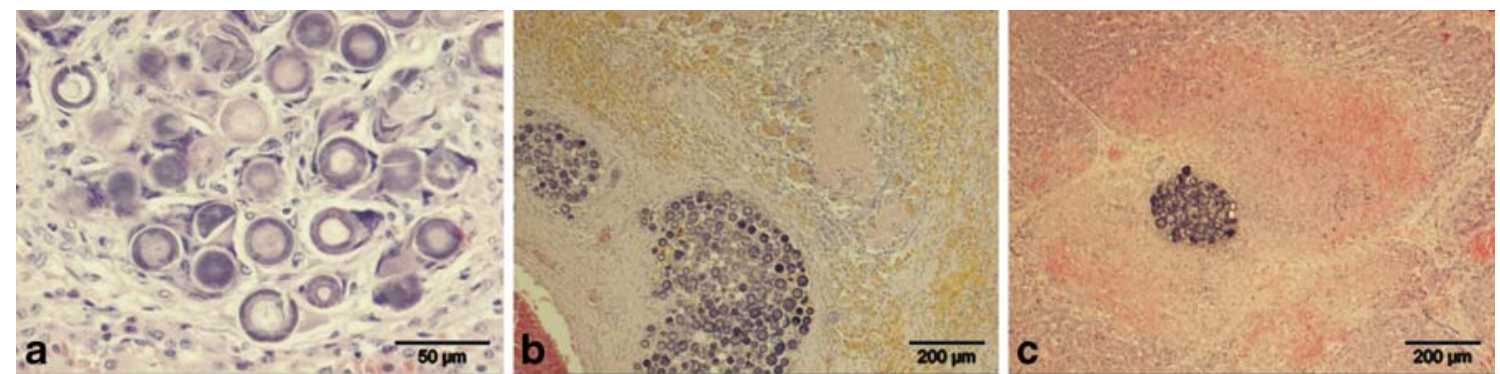
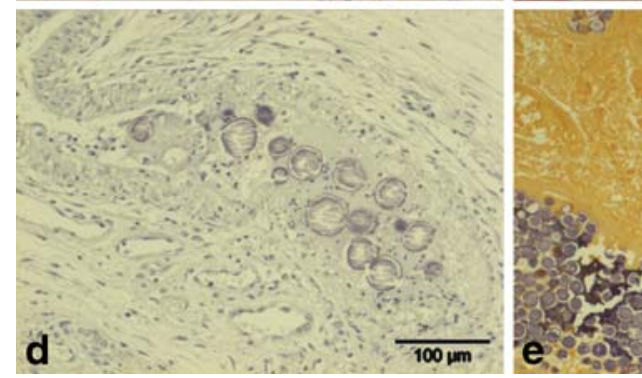

Fig. 4 a Liver of pig $3\left({ }^{165} \mathrm{HoMS}\right)$ : aggregate of microspheres within a hepatic artery with fibrosis and multinucleated giant cells. $\mathbf{b}$ Liver of pig $3\left({ }^{165} \mathrm{HoMS}\right)$ : large portal area with necrosis surrounded by macrophages and multinucleated giant cells and a fibrous capsule with large aggregates of microspheres. c Liver of pig 8 ( $\left.{ }^{166} \mathrm{HoMS}\right)$ : a confined moderate-sized aggregate, probably within a hepatic artery, surrounded by hepatic necrosis and hemorrhage of the surrounding parenchyma and partial necrosis of the portal structures. $\mathbf{d}$ Stomach of

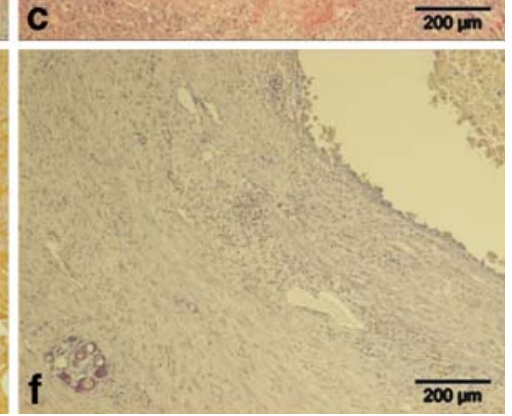

pig $10\left({ }^{166} \mathrm{HoMS}\right)$ : submucosal artery with microspheres associated with fibrinoid deposition and necrosis of the arterial wall. e Liver of pig 11 ( $\left.{ }^{166} \mathrm{HoMS}\right)$ : large area with yellow necrosis and a large aggregate of microspheres within a necrotic hepatic artery. f Gallbladder of pig 16 ( $\left.{ }^{166} \mathrm{HoMS}\right)$ : lumen filled with necrotic debris, macrophages, and some neutrophils. Marked fibrosis of the wall with an aggregate of microspheres within an artery 

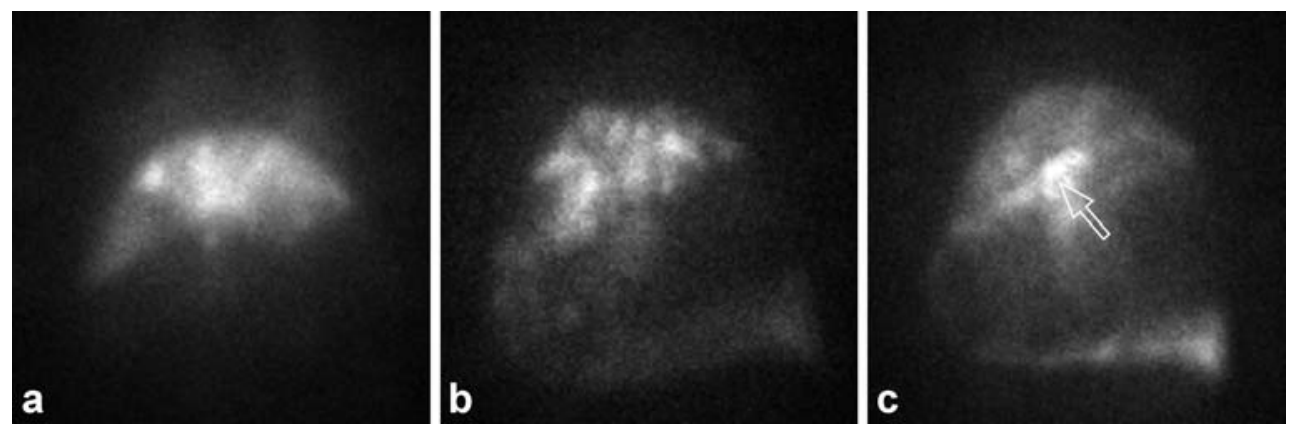

Fig. 5 Nuclear images of pigs administered ${ }^{166} \mathrm{HoMS}$. Planar nuclear scan of pig 15, demonstrating highly selective deposition of ${ }^{166} \mathrm{HoMS}$ microspheres in the liver (a); planar nuclear scan of pig 18, on which a substantial amount of ${ }^{166} \mathrm{Ho}(17.4 \%)$ is revealed to be present in the

septic endocarditis, which will have brought about distress and anorexia, it is more likely that the ulcers, hence the persistent blood loss, were associated with this comorbidity. During the course of the experiments, the use of chronic intravascular catheters has proved to be ideal, both for the administration of intravenous medication and for obtaining blood samples. However, it must be stressed that, to minimize the risk of catheter-related infections or even sepsis, these devices should be operated in a strictly sterile manner.

The key component of a toxicity study is usually the pharmaceutical compound that is administered to the animal. In this radioembolization study, as well as the pharmaceutical quality of the microspheres, a very important factor was the manner in which the catheterization-microsphere administration procedure was carried out. The most important (lethal) complication that has occurred was inadvertent deposition of an excessive amount of ${ }^{166} \mathrm{HoMS}$ in the gastric wall (b); planar nuclear scan of pig 10, demonstrating excessive amounts of radioactivity $(52.5 \%$ of injected dose) present in the stomach. An intense hotspot in the lesser curvature of the stomach is depicted by the arrow (c)
Fig. 6 In vivo coronal $(\mathbf{a}-\mathbf{c})$ and transverse $(\mathbf{d}-\mathbf{f}) \mathrm{MR}$ images of pig 17. The anatomical images are found in a and d ( $T_{1}$-weighted $\left.\mathrm{SE}\right)$, and $\mathbf{b}$ and e ( $T_{2}$-weighted $\mathrm{SE}$ images). c and $\mathbf{f}$ The holmium-sensitive $T_{2}{ }^{*}$-weighted GE images. In the $T_{1}$-weighted SE images, the vessels and gallbladder show up as hypo-intense structures and as hyperintense structures in the $T_{2}$-weighted SE images. In the $T_{2}$ *-weighted GE images, the clusters of microspheres are visualized as additional focal regions of signal loss, especially in the dorsal region
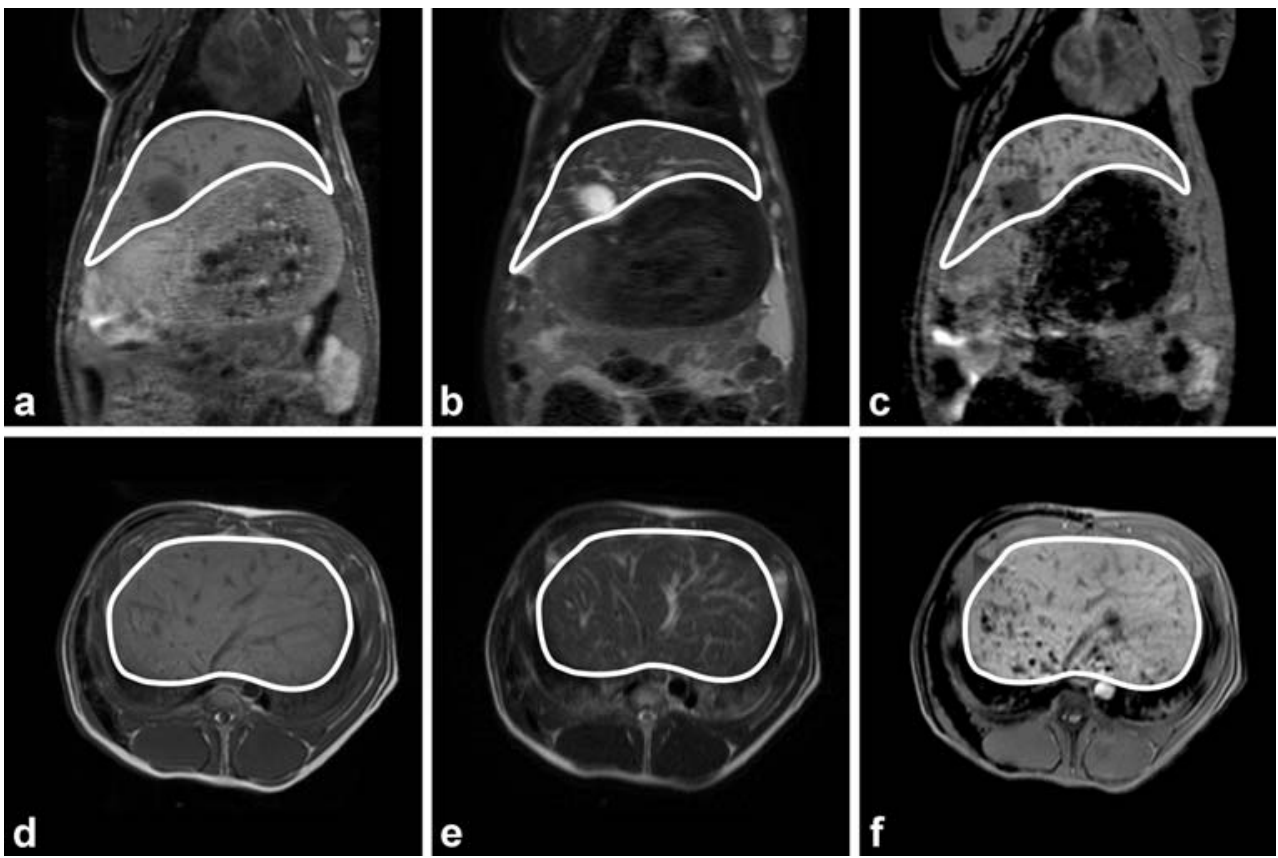

gastric wall (pigs 8 and 10), as a consequence of which perforating ulcers were induced. The cause of this radioembolization of the stomach was most probably unintentional injection of microspheres into the gastroduodenal artery, as a result of inaccurate catheter positioning, and/or too high a force applied to flush the microspheres into the proper hepatic artery, thus resulting in retrograde flow. Catheter manipulation can also lead to vasospasm, for which pigs are predisposed, further increasing the risk of backflow. In the last six experiments, the specific activity of the ${ }^{166} \mathrm{HoMS}$ was increased (from $\sim 10$ to $\sim 25 \mathrm{MBq} / \mathrm{mg}$ ); hence, the amount of microspheres to be administered significantly decreased (Table 2). Until these experiments, a hockey-stick-shaped catheter was used, both to pass the celiac axis and to administer the microspheres. To reduce the risk of backflow, in the subsequent experiments, the microspheres were administered using a straight-tip catheter. 
Furthermore, in the last eight experiments, an iodine contrast agent (Telebrix $\left.{ }^{\circledR} 35\right)$ was added to the flushing fluid (50:50) to be able to monitor for backflow using X-ray C-arm imaging. In the remaining experiments, deposition of excessive amounts of ${ }^{166} \mathrm{HoMS}$ into the gastric wall did not occur, although, in four cases, there was still some radioactivity $(<20 \%$ of injected dose) present in the stomach wall. Backflow into A. gastroduodenalis still cannot be fully excluded, but it is more likely that a portion of the microspheres ended up in the A. gastrica dextra (Fig. 1), which branches off the hepatic artery distally from the site of the catheter tip positioning during administration. It has been reported in the literature (on human patients) that both A. gastroduodenalis and A. gastrica dextra are able to be prophylactically occluded, usually by coiling [33, 34]. As the aim was for the whole liver to be exposed to the treatment, superselective microsphere administration was not performed.

As the focus of this study was not on imaging but on potential toxic side effects of these microspheres and because quantitative SPECT analysis will only be available in the near future, this was refrained from and the SPECT scans merely analyzed in a semi-quantitative fashion. It was opted instead to quantify the actual biodistribution by measuring the ${ }^{166 \mathrm{~m}}$ Ho content in the ex vivo organs. The nuclear imaging did prove very useful for the detection of radioactivity deposition into the lungs. As mentioned earlier, MRI could not exclude holmium microsphere presence in the lungs or (hardly) in the stomach wall. However, it could be used to detect shunting to the lungs by measuring the holmium content in blood passing through the Vena cava caudalis, as was proposed in a previous paper [15].

In this study, it was demonstrated that pigs can cope with extremely high liver absorbed doses, up to over 100 Gy in nine experiments. The maximum organ dose to the (human) liver from external beam radiation is approximately 30 35 Gy $[35,36]$ or well below the range where tumoricidal effects can be expected. Apart from biological effective dose considerations like differences in dose rate, one explanation for this phenomenon is the distinctly inhomogeneous intrahepatic distribution of radioactivity, as was visualized by the nuclear and MRI scans.

Despite the overall lack of clinical signs in the pigs or, more specifically, symptoms of liver disease, postmortem examinations did reveal abnormalities in most of the animals. The extent and severity of the abnormalities differed considerably between the two groups. In the animals which had been injected with ${ }^{165}$ HoMS, only very mild liver changes were observed, whereas the livers that had been exposed to ${ }^{166}$ HoMS showed blatant changes, i.e., gross atrophy (accompanied with compensatory hypertrophy) and (microscopic) coagulative necrosis of parts of the livers. In itself, this is what can be expected after embolization of the hepatic artery with microspheres loaded with high amounts of a high-energy beta-emitting radionuclide.

In the monitored hematological parameters, no alterations were seen (except in the animals that suffered from persistently bleeding ulcers). The absence of myelosuppression was as expected because, in previously conducted in vitro and in vivo studies, it was demonstrated that only a very small fraction of the holmium-166 is released from the microspheres [37-39]. Overall, hematochemical abnormalities were absent, with the exception of the AST levels in the ${ }^{166}$ Ho group; a transient rise in which these levels roughly doubled from samples 2 to 3 (Fig. 2d) was seen, which is in accordance with the postmortem findings, specifically the presence of ischemic/necrotic tissue for which AST is an indicator in the pig [40], and this accords also with the literature on ${ }^{90} \mathrm{Y}$ microsphere treatment, in which a transient rise in the liver enzymes serum levels is usually reported [34, 41].

After chemoembolization, the incidence of the so-called post-embolization syndrome, which includes fatigue, nausea, emesis, and/or right upper quadrant pain, is very high [42, 43]. These symptoms have been reported after ${ }^{90} \mathrm{Y}$ microsphere infusion as well but the incidence is low $[2,44]$. Therefore, as expected, in this pig study, no vomiting was seen as well even if appetite was usually temporarily decreased. The animals exhibited no signs of abdominal pain.

Despite the fact that the cystic artery, which conveys blood to the gallbladder, branches off the right medial hepatic artery distally, similarly to A. gastrica dextra, gallbladder pathology was observed in only two animals. It can be postulated that the reason for the absence of pathological findings in the gallbladders of the other pigs is that premedication consisted of atropine, which blocks parasympathetic activity, resulting in a decreased blood flow in this feeble artery during the microsphere administration. Gallbladder pathology (radiation cholecystitis) subsequent to ${ }^{90} \mathrm{Y}$ microsphere treatment is a frequently described complication in the literature [9, 45]. Nevertheless, in most centers, a cholecystectomy preceding ${ }^{90} \mathrm{Y}$ microsphere therapy is not standard procedure.

Before patients undergo treatment with ${ }^{90} \mathrm{Y}$ microspheres, a nuclear scan is acquired after hepatic arterial injection with technetium-99m-labeled macroaggregates. One of the reasons for this is to monitor for and/or quantify hepatopulmonary shunting, as excessive delivery of microspheres into the lungs can obviously lead to pulmonary failure. Whereas in (primary) liver cancer patients, all kinds of anomalous arteriovenous connections commonly exist [34], this is not usually the case in healthy humans or in healthy pigs. Therefore, as could be expected, no radioactivity was detected in the lungs in any of the experiments, neither on any of the scans nor on histological slides. 
In this study, the critical factor has been demonstrated to be the administration technique. In summary, the catheter should be positioned correctly, i.e., the tip distally from where A. gastroduodenalis branches off the common hepatic artery, and the flushing force/rate kept low. In addition, the specific activity of the microspheres should be sufficiently high, and backflow should be monitored or altogether inhibited by coiling.

It can be concluded that the toxicity profile of the holmium poly(L-lactic acid) microspheres is low. If the microspheres were administered in a correct manner, viz. deposited selectively into the liver, hepatic arterial embolization in pigs, with ${ }^{166} \mathrm{HoMS}$ in high doses, was well tolerated and the clinical side effects notably mild. Owing to the favorable outcome of this animal study, phase 1 clinical trials are being planned for the near future.

Acknowledgment This research was financially supported by the Dutch Technology Foundation STW (UGT.6069). The authors would also like to thank Dr. M.W. Konijnenberg (Mallinckrodt Inc., Tyco Healthcare, Petten, The Netherlands) for supplying us with the $S$ values for ${ }^{166} \mathrm{Ho}$ and Miss Rosanne Varkevisser, B.Sc., for conducting the ex vivo radioactivity measurements.

Conflict of interest statement There is no conflict of interest to declare.

Open Access This article is distributed under the terms of the Creative Commons Attribution Noncommercial License which permits any noncommercial use, distribution, and reproduction in any medium, provided the original author(s) and source are credited.

\section{References}

1. Garrean S, Muhs A, Bui JT, Blend MJ, Owens C, Helton WS, et al. Complete eradication of hepatic metastasis from colorectal cancer by Yttrium-90 SIRT. World J Gastroenterol 2007;13:3016-9.

2. Sato K, Lewandowski RJ, Bui JT, Omary R, Hunter RD, Kulik L, et al. Treatment of unresectable primary and metastatic liver cancer with yttrium-90 microspheres (TheraSphere(R)): assessment of hepatic arterial embolization. Cardiovasc Interv Radiol 2006;29:522-9.

3. Sangro B, Bilbao JI, Boan J, Martinez-Cuesta A, Benito A, Rodriguez J, et al. Radioembolization using 90Y-resin microspheres for patients with advanced hepatocellular carcinoma. Int J Radiat Oncol Biol Phys 2006;66:792-800.

4. Kennedy AS, Coldwell D, Nutting C, Murthy R, Wertman DE Jr., Loehr SP, et al. Resin (90)Y-microsphere brachytherapy for unresectable colorectal liver metastases: modern USA experience. Int J Radiat Oncol Biol Phys 2006;65:412-25.

5. Van Hazel G, Blackwell A, Anderson J, Price D, Moroz P, Bower G, et al. Randomised phase 2 trial of SIR-spheres plus fluorouracil/leucovorin chemotherapy versus fluorouracil/ leucovorin chemotherapy alone in advanced colorectal cancer. J Surg Oncol 2004;88:78-85.

6. Andrews JC, Walker SC, Ackermann RJ, Cotton LA, Ensminger WD, Shapiro B. Hepatic radioembolization with yttrium-90 containing glass microspheres: preliminary results and clinical follow-up. J Nucl Med 1994;35:1637-44.

7. Nijsen JFW, Van het Schip AD, Hennink WE, Rook DW, Van Rijk PP, De Klerk JMH. Advances in nuclear oncology: microspheres for internal radionuclide therapy of liver metastases. Current Med Chem 2002;9:73-82.

8. Ho S, Lau JW, Leung TW. Intrahepatic (90)Y-microspheres for hepatocellular carcinoma. J Nucl Med 2001;42:1587-9.

9. Murthy R, Nunez R, Szklaruk J, Erwin W, Madoff DC, Gupta S, et al. Yttrium-90 microsphere therapy for hepatic malignancy: devices, indications, technical considerations, and potential complications. Radiographics 2005;25(Suppl 1):S41-55.

10. Murthy R, Xiong H, Nunez R, Cohen AC, Barron B, Szklaruk J, et al. Yttrium 90 resin microspheres for the treatment of unresectable colorectal hepatic metastases after failure of multiple chemotherapy regimens: preliminary results. J Vasc Interv Radiol 2005; 16:937-45.

11. Popperl G, Helmberger T, Munzing W, Schmid R, Jacobs TF, Tatsch K. Selective internal radiation therapy with SIR-Spheres in patients with nonresectable liver tumors. Cancer Biother Radiopharm 2005;20:200-8.

12. De Wit TC, Xiao J, Nijsen JF, Van het Schip AD, Staelens SG, Van Rijk PP, et al. Hybrid scatter correction applied to quantitative holmium-166 SPECT. Phys Med Biol 2006;51:4773-87.

13. Ho S, Lau WY, Leung TW, Chan M, Chan KW, Lee WY, et al. Tumour-to-normal uptake ratio of $90 \mathrm{Y}$ microspheres in hepatic cancer assessed with 99Tcm macroaggregated albumin. $\mathrm{Br} \mathrm{J}$ Radiol 1997;70:823-8.

14. Seppenwoolde JH, Nijsen JF, Bartels LW, Zielhuis SW, Van het Schip AD, Bakker CJ. Internal radiation therapy of liver tumors: qualitative and quantitative magnetic resonance imaging of the biodistribution of holmium-loaded microspheres in animal models. Magn Reson Med 2004;53:76-84.

15. Nijsen JF, Seppenwoolde JH, Havenith T, Bos C, Bakker CJ, Van het Schip AD. Liver tumors: MR imaging of radioactive holmium microspheres - phantom and rabbit study. Radiology 2004;231:491-9.

16. Seppenwoolde JH, Bartels LW, Van der Weide R, Nijsen JF, Van het Schip AD, Bakker CJ. Fully MR-guided hepatic artery catheterization for selective drug delivery: a feasibility study in pigs. J Magn Reson Imaging 2006;23:123-9.

17. Zielhuis SW, Nijsen JF, Dorland L, Krijger GC, Van het Schip AD, Hennink WE. Removal of chloroform from biodegradable therapeutic microspheres by radiolysis. Int J Pharm 2006;315: 67-74.

18. Zielhuis SW, Nijsen JFW, De Roos R, Krijger GC, Van Rijk PP, Hennink WE, et al. Production of GMP-grade radioactive holmium loaded poly(L-lactic acid) microspheres for clinical application. Int J Pharm 2006;311:69-74.

19. Nijsen JFW, Van het Schip AD, Van Steenbergen MJ, Zielhuis SW, Kroon-Batenburg LM, Van de Weert M, et al. Influence of neutron irradiation on holmium acetylacetonate loaded poly (L-lactic acid) microspheres. Biomaterials 2002;23:1831-9.

20. Nijsen F, Rook D, Brandt C, Meijer R, Dullens H, Zonnenberg B, et al. Targeting of liver tumour in rats by selective delivery of holmium-166 loaded microspheres: a biodistribution study. Eur J Nucl Med 2001;28:743-9.

21. Nijsen JFW. Radioactive holmium poly(L-lactic acid) microspheres for treatment of hepatic malignancies: efficacy in rabbits. $\mathrm{PhD}$ thesis Utrecht University, The Netherlands 2001, pp. 109-122. ISBN 90-393-2685-1.

22. Vente MA, Hobbelink MG, Van het Schip AD, Zonnenberg BA, Nijsen JF. Radionuclide liver cancer therapies: from concept to current clinical status. Anticancer Agents Med Chem 2007;7: 441-59.

23. Nijsen JFW, Zonnenberg BA, Woittiez JR, Rook DW, SwildensVan Woudenberg IA, Van Rijk PP, et al. Holmium-166 poly lactic 
acid microspheres applicable for intra-arterial radionuclide therapy of hepatic malignancies: effects of preparation and neutron activation techniques. Eur J Nucl Med 1999;26:699-704.

24. Zielhuis SW, Nijsen JFW, Figueiredo R, Feddes B, Vredenberg AM, Van het Schip AD, et al. Surface characteristics of holmiumloaded poly(L-lactic acid) microspheres. Biomaterials 2005; 26:925-32.

25. Boxenbaum $H$. Interspecies variation in liver weight, hepatic blood flow, and antipyrine intrinsic clearance: extrapolation of data to benzodiazepines and phenytoin. J Pharmacokinet Biopharm 1980;8:165-76.

26. Dondelinger RF, Ghysels MP, Brisbois D, Donkers E, Snaps FR, Saunders J, et al. Relevant radiological anatomy of the pig as a training model in interventional radiology. Eur Radiol 1998; 8:1254-73.

27. Faustini M, Munari E, Colombani C, Russo V, Maffeo G, Vigo D. Haematology and plasma biochemistry of Stamboek pre-pubertal gilts in Italy: reference values. J Vet Med A Physiol Pathol Clin Med 2000;47:525-32.

28. Hannon JP, Bossone CA, Wade CE. Normal physiological values for conscious pigs used in biomedical research. Lab Anim Sci 1990;40:293-8.

29. Odink J, Smeets JF, Visser IJ, Sandman H, Snijders JM. Hematological and clinicochemical profiles of healthy swine and swine with inflammatory processes. J Anim Sci 1990;68:163-70.

30. Guise HJ, Carlyle WW, Penny RH, Abbott TA, Riches HL, Hunter EJ. Gastric ulcers in finishing pigs: their prevalence and failure to influence growth rate. Vet Rec 1997;141:563-6.

31. Sidikou DI, Banga-Mboko H, Tamboura HH, Hornick JL, Remy B, Beckers JF. Correlation between a proteolytic method and a radioimmunoassay for porcine serum pepsinogen concentrations. Res Vet Sci 2006;80:260-6.

32. Banga-Mboko H, Tamboura H, Maes D, Traoré H, Youssao I, Sangild PT, et al. Survey of gastric lesions and blood pepsinogen levels in pigs in burkina faso. Vet Res Commun 2003;27:595602 .

33. Murthy R, Brown DB, Salem R, Meranze SG, Coldwell DM, Krishnan S, et al. Gastrointestinal complications associated with hepatic arterial yttrium-90 microsphere therapy. J Vasc Interv Radiol 2007;18:553-61.
34. Salem R, Thurston KG, Carr BI, Goin JE, Geschwindt JF. Yttrium-90 microspheres: radiation therapy for unresectable liver cancer. J Vasc Interv Radiol 2002;13:S223-9.

35. Cromheecke M, Konings AW, Szabo BG, Hoekstra HJ. Liver tissue tolerance for irradiation: experimental and clinical investigations. Hepatogastroenterology 2000;47:1732-40.

36. Ingold J, Reed G, Kaplan H, Bagshaw M. Radiation hepatitis. Am J Roentgenol Radium Ther Nucl Med 1965;93:200-8.

37. Zielhuis SW, Nijsen JFW, Seppenwoolde JH, Bakker CJG, Krijger GC, Dullens HFJ, et al. Long-term toxicity of holmium loaded poly(L-lactic acid) microspheres in rats. Biomaterials 2007; 28:4591-9.

38. Zielhuis SW, Nijsen JFW, Krijger GC, Van het Schip AD, Hennink WE. Holmium-loaded poly(L-lactic acid) microspheres: in vitro degradation study. Biomacromolecules 2006;7:2217-23.

39. Van Es RJ, Nijsen JF, Van het Schip AD, Dullens HF, Slootweg PJ, Koolen R. Intra-arterial embolization of head-and-neck cancer with radioactive holmium-166 poly(L-lactic acid) microspheres: an experimental study in rabbits. Int J Oral Maxillofac Surg 2001;30:407-13.

40. Jeppsson B, Dahl EP, Fredlund PE, Stenram U, Bengmark S. Hepatic necrosis in the pig produced by transient arterial occlusion. Eur Surg Res 1979;11:243-53.

41. Garrean S, Espat NJ. Yttrium-90 internal radiation therapy for hepatic malignancy. Surg Oncol 2005;14:179-93.

42. Ramsey DE, Kernagis LY, Soulen MC, Geschwind JF. Chemoembolization of hepatocellular carcinoma. J Vasc Interv Radiol 2002;13:S211-21.

43. Leung DA, Goin JE, Sickles C, Raskay BJ, Soulen MC. Determinants of postembolization syndrome after hepatic chemoembolization. J Vasc Interv Radiol 2001;12:321-6.

44. Salem R, Lewandowski R, Roberts C, Goin J, Thurston K, Abouljoud M, Angi C. Use of yttrium-90 glass microspheres (TheraSphere) for the treatment of unresectable hepatocellular carcinoma in patients with portal vein thrombosis. J Vasc Interv Radiol 2004;15:335-45.

45. Miller FH, Keppke AL, Reddy D, Huang J, Jin J, Mulcahy MF, et al. Response of liver metastases after treatment with yttrium-90 microspheres: role of size, necrosis, and PET. Am J Roentgenol 2007;188:776-83. 